Article

\title{
Sustainability, Learning and Capability: Exploring Questions of Balance
}

\section{William A. H. Scott * and Stephen R. Gough}

Centre for Research in Education and the Environment, University of Bath, Claverton Down, Bath, BA2 7AY, UK; E-Mail: s.r.gough@bath.ac.uk

* Author to whom correspondence should be addressed; E-Mail: w.a.h.scott@bath.ac.uk.

Received: 27 October 2010; in revised form: 26 November 2010 / Accepted: 1 December 2010 /

Published: 3 December 2010

\begin{abstract}
It is argued that sustainable development makes best sense as a social learning process that brings tangible and useful outcomes in terms of understanding and skills, and also reinforces the motivation and capability for further learning. Thus, there are always balances to be struck between a broad-based, wide-ranging education and a more specialist one; between a focus on ideas themselves, and on their application in social or economic contexts; and between keeping ideas separate, and integrating them. This paper will explore the nature of such balances, and the issues to bear in mind when striking them, focusing on schools, university and college contexts within the United Kingdom.
\end{abstract}

Keywords: learning; capability; sustainability; further education; higher education; ESD; citizenship; TVET; interdisciplinarity

\section{Introduction}

John Foster [1] has made a telling contribution to our understanding by arguing that sustainable development makes no sense other than as a social learning process of improving the human condition that can be continued indefinitely without undermining itself. He argues that sustainable development doesn't depend on learning; rather, it's inherently a learning process of making the emergent future ecologically sound and humanly habitable, as it emerges through the continuous responsive learning which, Foster says, is the human species' most characteristic endowment. See Scott \& Gough [2,3] for in-depth explorations of these ideas. 
Foster neatly captures the idea of learning as a collaborative and reflective process, the extension of this into an inter-generational dimension, and the idea of environmental limits. A crucial point about effective learning is that not only can it have tangible and immediately useful outcomes in terms of knowledge, understanding, skills, social action, etc, but it can also reinforce the capability and motivation for further learning-both individually and socially. As a consequence, a key outcome, especially in formal education programmes, is the enabling of successful transitions to the next stage of learning - whether in formal settings, in training, in work, or just in life. Whilst what is studied is obviously crucial, how we determine what this is to be is equally important, especially in relation to the understandings we bring to bear when making unavoidable choices in the selection from culture that, according to Lawton, curriculum always involves [4,5]. Research around such choice-making seems very limited, but much needed.

At any stage, there's always a balance to be struck between a broad-based, wide-ranging education and a more specialist one, between a focus on ideas themselves, and on their application in a social or economic context, and between keeping ideas separate, and integrating them. So, what do these tensions mean for sustainable development, and education for sustainable development (ESD), particularly in the formal education sector?

It seems clear that all three formal sectors - schools, colleges and universities - have vital, but different, roles. Stables [6,7] argues that, up to age16, there needs to be an emphasis on getting across a general, and probably rather diffuse understanding of, and sense of concern for, sustainability. This necessarily involves a broad-based approach with a focus on both the school's internal and external social contexts, not only as places that provide scope for learning, but also where socio-economic change is both possible and necessary. As young people get older, going to college and university, the need for greater specialisation, and specific, job-related education and training, becomes a more pressing need, and a focal point of study. In what follows we explore these ideas in relation to formal education across its various contexts and sectors. As a preliminary step, however, we should note that all of this takes place in the overarching context of a global shift towards associating education primarily with the transmission of skills, while placing responsibility for this process upon the learner rather than society more widely. As Brown and Lauder [8] note:

The focus on individual responsibility (supply side) rather than a political commitment to job creation (demand side) is a political sleight of hand that shifts the responsibility for employment firmly onto the shoulders of individuals rather than the state.

This is important to our discussion because learners begin from the opportunities, constraints and obligations they believe themselves to have. Any educational intervention needs to respect this if it is to be effective. The key point in the paper is that, whether manifest as a broad course or narrow specialism, whether designed to raise awareness or develop skills, and whether in schools, colleges or universities, ESD can helpfully be seen as an education in citizenship: a responsive social learning process which is a preparation for informed, open-minded, social engagement with the main existential issues of the day that can be experienced in the family, the community and workplace; in all aspects of a lifelong learning. 


\section{Schools}

The English sustainable schools initiative (2005-2010) stressed the idea that schools need to be role models for communities and society. Five years ago, the UK government issued a consultation paper on delivering UK sustainable development strategy [9] that began:

DfES [The Department for Education and Skills] has reaffirmed its commitment to sustainable development by publishing a two-year action plan to achieve outcomes to underpin a sustainable society. Schools are a key strand of this action plan and are invited to become models of sustainable development for their communities.

In a speech on climate change, in May 2004, Prime Minister Blair had laid the foundation for these developments:

Sustainable development will not just be a subject in the classroom: it will be in its bricks and mortar and the way the school uses and even generates its own power. Our students won't just be told about sustainable development, they will see and work within it: a living, learning place in which to explore what a sustainable lifestyle means.

These ideas suggest a strong social change focus with emphases, for example, on reducing energy usage and the carbon footprint, increasing social participation, and enhancing biodiversity. This broad-based approach has the development of capability to make a social contribution in relation to sustainability at its heart. It is clearly about an active citizenship although this is not necessarily always made explicit. There is an academic element, of course, which imparts some limited specialist knowledge, and which is mainly experienced through subjects such as science, geography, and design technology [10], but also across the breadth of the curriculum. Schools that know what they are doing will integrate these approaches, but we do not yet know enough about how most effectively this can be done, other than to say that committed school leadership is the key to any successful, and enduring, development [7,11,12]. Specialist knowledge becomes increasingly available, and more detailed, as learners mature, and there is more chance for external agencies and the media to influence - or perhaps lead-learning. Stables [6] asks, reasonably, who could ever know where the balance between these lies. The link to living, social engagement, and the wider world of employment, certainly acquires a greater imperative with age - through greater personal relevance as time passes and as jobs, careers and further study loom.

Unfortunately, there has been an overemphasis in schools on personal agency with a tendency to view the student as an individual actor who ought to know what to do and what not to do, in relation, for example, to recycling, saving energy, and reducing waste. This ensures an emphasis on things that are relatively easy to do by individuals, as opposed to actions that people are not able to do on their own - such as getting a school or other organisation to change its procurement policy and practice, and so cut down waste in the first place. This, essentially individualised view, neglects the picture of the student as a social and more public actor-as someone engaged in the messy but vital business of democratic citizenship that is so central to the received view of sustainable development and ESD [13]. Such actions relate to the formulation and critique of public policy (both national and local), and to purposive interaction with social institutions about their practice - the sort of macro social change that can make a real difference to people's lives and community well-being. By and large, schools tend not to emphasise this view of action, particularly once the primary phase has been left behind. It can, of 
course, be somewhat political in nature, but, then, that is the whole point. Stables [6] has argued that the prime curriculum focus in schools now should be on the development of skills of critical thinking, dialogue and debate, with environment and sustainability one of many possible focuses. Stables argues that, whilst openness to the real public debate is crucial, it is vital to remember that capacities are not outcomes, that they don't simply precede outcomes, and that, to a large extent, it is the making of real-life decisions that most fully develops the capacity for exercising responsible citizenship. This seems a good reason to enable students to begin to practise such real-life, decision-making in schools, and citizenship seems the most appropriate - and mainstream — niche within which schools can pursue ideas around sustainability. Keating et al. and Ofsted (2010) provide a fuller exploration of this argument [14,15].

Unfortunately, this insight that ESD will have good (and perhaps maximal) impact when seen as citizenship education remains largely obscured and schools lose an opportunity to mainstream ESD. It also means that citizenship itself remains something of a quasi-subject looking for a useful purpose. The priority that is argued for here is for schools to help young people to develop citizenly awareness, understanding, skills, and motivations. Research evidence suggests that schools that are experienced in sustainability work do appreciate this imperative and its whole-school nature [16-18]. It is not, however, very widespread, and surely needs to be both a developmental, and research, priority.

\section{Higher Education}

The student experience in higher education (HE) is quite different from that in schools as HE courses tend to focus on specialist and discipline-specific matters, rather than on the broad-based, community and citizenly, focus that we've seen with schools. Although there are attempts to broaden this out, for example, $[19,20]$, doing so remains problematic, as does making sense of the currently fashionable, but rather unfocused, talk about sustainability literacy as some common entitlement of all higher education students $[21,22]$. This seems likely to remain a hope rather than a reality, although a research focus here will surely continue.

In the Higher Education Funding Council for England's (Hefce) most recent research on teaching about sustainable development in English universities [23], it was almost wholly discipline-related activity that was found, and, of course, the UK's Higher Education Academy, with its remit on curriculum development in the HE sector, works largely through subject centres. The Academy's ESD Project is currently preparing guidance for universities wishing to embed sustainability into curricula and wider activities. Another element of all this is what the sustainable schools initiative has termed the necessary integration between curriculum, campus, and community: that is, what is learned should be integrated with the management (in both human and resource senses) of the campus, and institution, and with activity in the community. Thus, attempts at the local sourcing of food, and issues such as fair trade, are significant elements within many schools with attempts to integrate these into what is taught. There is less scope for this within universities where integration only occurs if such a focus makes contingent sense to academics responsible for particular degree courses: engineering and management come immediately to mind here. Certainly, It is unlikely to be directed by senior managers (as it is in schools), or wished upon institutions by funding councils (as it was by the government through its sustainable schools initiative). The University of Plymouth's Centre of Excellence in Teaching and 
Learning, which gave rise to its Centre for Sustainable Futures, is one of only a handful of notable exceptions here, and its history shows something of how the interplay of managers, academics, students and institutional leaders is both complex and contingent upon a wide range of contextual factors.

Having said this, it does seem sensible for HE institutions' current attempts to reduce their ecological footprint and carbon usage (as encouraged by Hefce through, for example, its 2010 policy on carbon reduction which includes a clear focus on learning by and across institutions), to be carried out in partnership with students and other major stakeholders in the process, and the scope for research here appears to be considerable. It seems likely, however, that this will best be done in partnership with the National Union of Students and individual student unions, rather than with volunteer or special interest groups, and interesting examples of practice can already be found, with on-going research funded by Hefce and the Academy. This is, of course, a form of citizenship activity [24], though it is not usual to find it referred to as such.

Expertise in relation to teaching and sustainability within higher education is more likely to be found within disciplines, and academics are likely to see themselves as advancing or developing the subject, say, engineering education, rather than ESD. This brings them several advantages, most significant of which is that other academics are likely to understand what they are trying to do, and take them seriously, because they share a conceptual framing. Where the nature of work, and what it means to be a competent professional, is changing, because of the need to address sustainability, we find calls for new graduates to be well prepared. It is this pull from the professions and employers which gives rise to a major impetus for change, as well as the interests (that is, the push) of academics, and sometimes, students. In schools, this pull element is very limited. What there has been, has come from government and organisations such as the, now defunct, Qualifications and Curriculum Authority [10]. However, the latter's agency was always much less effective than that of the professions on universities because of the powerful professional influence on degree accreditation processes. This interface with the workplace, where the sustainability issues faced by society are prominent, can be a significant factor in course and degree re-design, and there are examples of this across the entire higher education disciplinary spectrum, as the Hefce research shows [23]. See also Sterling \& Scott [25,26] who review the development of interest in sustainability across the English higher education sector. How these changes might most usefully be extended and embedded remains appropriately contentious, particularly in the current (2010) context of radical change in the funding and governance of higher education in some countries, and particularly in England. As such, however, it does constitute very fertile research ground.

\section{Further Education; Technical and Vocational Education and Training}

We treat further education (FE) and technical and vocational education and training (TVET) together in a single section because they overlap significantly, although not perfectly: much TVET takes place in FE colleges: but not all; and not everything that happens in FE colleges is TVET.

In principle, the analysis of curriculum in the previous section applies to FE as well as to HE, especially in relation to the growing significance of sustainability issues in the job market where the need for college and university graduates alike to be able to understand and comply with the growing 
incidence of sustainability-focused regulations and laws in the workplace, and to be able to explain and justify these to customers and clients, are growing phenomena. Thus it is that students on such courses might well be able to experience a focus on sustainability as a natural emphasis and content where this can also be reinforced through direct contact with employers in work placements and the like.

However, a focus in further education and the adult skills sector was more slow to develop than in schools and universities, and has proved more patchy. The sector's first sustainability strategy was developed by the Learning and Skills Council (LSC) in 2005. This focused in particular on estates, curriculum and community, and gave rise to awareness raising and a number of projects about climate change and other sustainable development issues. The overall aim was to promote a culture change such that sustainability became integral to the work and thinking of the LSC itself and all those in the sector. The LSC was replaced by the Skills Funding Agency in 2010, and it is too soon to judge whether this body will be any better at this sort of enabling than the LSC. Meanwhile, the Learning and Skills Improvement Service (LSIS) has promoted ESD through an emphasis on leadership and management. More recently, there have been government consultations [27] on how we are to meet the skills challenge in our shifts to a low carbon economy, and on skills for sustainable growth.

Although it is too soon to know the impact of such new emphases, there is already evidence of inherent tensions between perceived continuity and change that are the result of the significant differences between present and future skills needs. For example, as reported in the recent Unesco survey of ESD in the UK [13], those active learning styles that as seen as inherent to ESD tend to be difficult to link to colleges' approaches to sustainable development. This probably reflects the priority given by colleges to current vocational needs in response to government policy directives on skills, employers' needs and workforce development, with an understandable priority placed on current economic drivers rather than on the wider dimensions of education for sustainability. A further point is that vocational skills tend to be task-specific whereas a keen focus of the sustainability agenda necessarily involves interdisciplinarity. It also may be significant that sustainability interlinks the local and global, whereas vocational skills in colleges are normally framed locally and/or regionally.

In all this, the notion that the workplace has fundamentally changed because of the focus on sustainability is down-played within FE and, therefore, so is the idea of the employee as a social actor outwith the narrow specifics of getting a good job done; there is no hint of a citizenly role as there is with, say, current engineering undergraduates who know that, not only are there myriad laws and regulations to cope with, but also that the fundamental nature of being an engineer has changed, with its demands of being part of social groups negotiating project development, rather than being the professional who knows what to do, and how to do it. By and large, the tensions between continuity and change, and present and future skills, have greater force in FE colleges than in universities because the latter are not narrowly vocational to the same degree, and also because they are informed by current research which, as we explore later, is a peculiar and unique facet of the world of HE.

TVET is defined by UNEVOC - the organization set up by UNESCO to promote it - as being 'concerned with the acquisition of knowledge and skills for the world of work' (see: www.unevoc.unesco.org). As we note, above, unless we think of working as a part of the citizen's overall obligation, the citizenship element is pretty much absent. 
It is, in fact, potentially rather worse than this, since TVET has-at least in some countries - become associated with a kind of second-class citizenship. Wolf puts it as follows [28]:

We all have a fairly clear idea of what 'vocational' schooling means ... It does not mean a medical or veterinary degree; or a postgraduate law school course; or taking one's accountancy examinations while working for one of the big City accounting firms. It does not even mean nursing or teacher training. 'Vocational education' instead refers to courses for young people which are offered as a lower-prestige alternative to academic secondary schooling, and lead to manual, craft and, more recently, secretarial jobs. 'Technical education' slots into the hierarchy above vocational and below academic, and leads, in theory, to the technician jobs which increased in number during the twentieth century.

It is true, without doubt, that there are many examples around the world of TVET that does not conform to this dismal stereotype: but it is also true that it is a view with some justification, and one which is quite widely held [29]. In a way, this goes to the heart of the matter. A short digression into the history of ideas will help to explain why. In 1983, Stephen Kemmis [30] published a rather obscure paper that set out in simple form an idea that was afterwards very influential in the formation of ideas about environmental education and, subsequently, education for sustainable development. There are, he argued, three alternative views of education. The first of these he termed the 'job-slots' view. According to this, education exists to service the labour market. It is essentially a mechanism for social and economic reproduction. Kemmis argued (in a way which resonates strongly in the present) that such a view was not only impoverished, but also doomed to failure since it leaves no room for the adaptiveness required by both economy and education in the face of change.

The second alternative, according to Kemmis, was the 'cultured persons and survivors' view - broadly recognizable as a traditional liberal perspective - that aimed to produce self-motivated, independent, responsible, tolerant and able individuals. This Kemmis rejected on the grounds that it intrinsically failed to address, and in fact buttressed, the inequalities and injustices of capitalist society, notwithstanding frequent and no doubt well-meant attempts by its advocates to promote fairness and inclusion.

Finally, Kemmis identified the 'members of society' view of education, which aimed to facilitate social transformation through social critique and collaborative action. This view, powerfully underpinned by socially-critical theory, and with a commitment to action research that attracted many educators, was to have the strongest influence in the development, over the next twenty-five years or so, of environmental education and then education for sustainable development. We have argued elsewhere [2,3] that this socially-critical approach was, in fact, ultimately self-contradictory, since it insisted on individual and social self-determination while at the same time prescribing what the outcomes of that process must be. It was, in fact, an advocacy of Berlin's kind of 'positive freedom' [31]. See Gough [29] for a fuller discussion of this issue in the context of TVET.

The view we take here is broadly consistent with Christopher Winch's recent conception of 'liberal vocationalism', which has been developed with particular reference to TVET [32]:

Liberal vocationalism builds on the recognition, which has steadily gained ground since the discrediting of theories of unitary ability, that ability is actively specific and that abilities vary widely and are related to interests. It recognizes and celebrates the diversity of human life and aspirations. It also fulfils many of the main criteria of a liberal education: it initiates young people into worthwhile 
activities, building on cognitive breadth it seeks to provide cognitive depth in certain areas and it emphasises choice and forms of learning that are ethically acceptable. It parts company with traditional liberalism in putting limits on the depth to which 'forms of knowledge' are pursued and substitutes in their place more practical modes of knowledge.

This, we would argue, is consistent with a conception of sustainable development that is both internally robust, and a credible basis for ongoing negotiation and re-negotiation in modern societies. Perhaps most particularly, the liberal vocationalist insistence on a conception of what is 'worthwhile' opens the door to sustainability by inviting the reestablishment of the linkage between vocational education and (full, active) citizenship.

\section{The Unique Role of the University}

Finally, we turn to a unique feature of university work. We have argued in some detail elsewhere [33] that it is the unique research remit of higher education institutions, and their imperative of outreach into business and the community where research is disseminated, connections made, and social change engaged in and supported, that marks them out from institutions in the other formal sectors of education. It seems clear that university research and scholarly activity will continue to be key components of social progress-however we come to see this. Opportunities for sustainability-related research are growing as both research funders, business and third sector organisations see the need for appropriate research. It is worth noting, however, that potential for inter-disciplinary research - and its reporting-remains largely unrealised owing to a range of factors, some institutional, some disciplinary, and others external.

Uniquely, most of what a university does can be classified, one way or another, as teaching, research or administration. A particular tension exists across all three of these domains which we might think of as a tension between stability and change-between certainty and speculation. It is fuelled, on the one hand, by the obligation to archive, protect, apply, and bequeath existing knowledge; and, on the other, the imperative to challenge that knowledge, to break through into unexplored territory, and to go beyond problem-solving into comprehensive problem-redefinition. In the present, there is an expectation that everyone will face new, unimaginable circumstances in their lifetimes with which, in one way or another, and for better or worse, they will have to learn to deal. This means that the tension between the known and the unknown is now just as strong for teaching as it is for research. Whilst it is most marked for university teaching, it also applies to colleges and schools as well. Whilst at particular times and places we may want to stress knowledge transmission, or a challenge to that knowledge, inescapably now both are crucial - and this brings us back to ESD as citizenship education, and to Vare \& Scott's distinction between [34] ESD1 and ESD2 where ESD1 involves the promoting of informed behaviours, shifts in habit, and ways of thinking about how we live, where the need for this is clearly identified and agreed, and ESD2 concerns the building of capacity to think critically about — and beyond - what experts say, and to test out sustainable development ideas. It must follow from all this that universities (and to a lesser degree, colleges and schools) cannot in some instrumental fashion teach now for sustainable development in the future-the precise requirements for which will depend on a range of factors: some uncertain and some unknown. One of these is the influence of the research-informed higher education curriculum itself in determining those requirements. 
In the clearly liberal conception of a university, the institution, and the individuals they educate, should be at the cutting edge of society's creative response to unfolding future circumstances. This clearly is not achieved by making them the uncritical repositories of present conventional wisdom - whether in relation to higher education or sustainable development. A key current question is: 'what can education do for sustainable development?' But, a complementary one is: 'what can sustainable development do for education?' which leads to important questions such as: 'what is a university, a school or college now for?' One model of the social role of education is in accord with Amartya Sen's account of rational behaviour as the continuing development of preferences over what preferences to have, and of development as the capability, the substantive freedom to choose a life one has reason to value $[35,36]$. Thus, the whole of the formal education system should be promoting such rationality and freedom, as these qualities are firmly associated with the tolerance of a plurality of values that we shall need. How best we might do this is one of the many aspects of the research agenda in this field that deserve particular attention.

We concluded our 2007 book on higher education and sustainable development with this thought [33]:

Universities value knowledge, and for that reason they demand clarity about what is known, and how. Universities also value the pursuit of knowledge and must, therefore, insist on its present and on-going incompleteness - in the face of those who, for whatever reason, wish to extrapolate to final, general truths. Sustainable development touches on all aspects of our intellectual lives, and will require us to husband what we know, eschew glib certainties, and confront the future with an open, learning orientation. To this extent, there is an identity of interest between higher education and sustainable development.

This seems even more pertinent than when it was first written, even if we are no further on in knowing what it might mean on the ground.

\section{Final Thoughts}

The key point in this paper is that, whether manifest as a broad course or narrow specialism, whether designed to raise awareness or develop skills, and whether in schools, colleges or universities, ESD can helpfully be seen as an education in citizenship: a responsive social learning process which is a preparation for informed, open-minded, social engagement with the main existential issues of the day that can be experienced in the family, the community and workplace, indeed, in all aspects of lifelong learning. A key (research) question at every stage of this educational experience is where decisions need to be made about what to do, in the context of everything that we might do; another is how best to make such decisions. These are both questions worthy of careful, socially-inclusive deliberation. As has been argued throughout this paper, at every stage of the education process there are interconnected questions about how to determine the optimum balance between depth and breadth of study, and between the theoretically ideal and the socially practicable, in setting the instructional focus.

We have argued that the social context is an important focus throughout all aspects of formal education from primary school to college and university, and on to post-formal and work-related study, and that hence all such study, one way or another, has a citizenly element. In this sense, the social context is always both something that needs to be studied and researched, and a key parameter of such study and research (and on-going life and work). As students develop, they are able to acquire 
iteratively more nuanced conceptual understandings that engage the deep with the broad and the theoretical with the practical-if the education system provides the necessary prompts and opportunities. Finally, we need to say that we do not see the making of decisions about where to strike such balances as necessarily a negative thing, although doing so inevitably involves opportunity and transaction (process) costs. Further they are, of course, inherently problematic as they involve both Lawton's selection from culture with its ethical demands of deliberative process, and Foster's reflexive social learning.

We look forward to further discussion of, and research in, these important issues.

\section{References}

1. Foster, J. The Sustainability Mirage: Illusion and Reality in the Coming War on Climate Change; Earthscan: London, UK, 2008.

2. Scott, W.A.H.; Gough, S.R. Sustainable Development and Learning: Framing the Issues; RoutledgeFalmer: London, UK, 2003.

3. Key Issues in Sustainable Development and Learning: A Critical Review; Scott, W.A.H., Gough, S.R., Eds.; RoutledgeFalmer: London, UK, 2004.

4. Lawton, D. Educational Theory and Curriculum Planning; University of London: London, UK, 1973.

5. Lawton, D. Class, Culture and the Curriculum; Routledge: London, UK, 1975.

6. Stables, A.W.G. New worlds rising? Policy Futures Educ. 2010, 8, 588-596.

7. Scott, W.A.H. Developing the Sustainable School: Thinking the Issues Through; South West Learning for Sustainability Coalition: Ayleford, UK, 2010.

8. Brown, P.; Lauder, H. Globalization, Knowledge and the Myth of the Magnet Economy. In Education, Globalization and Social Change; Lauder, H., Brown, P., Dillabough, J., Halsey, A.H., Eds.; Oxford University Press: Oxford, UK, 2006; pp. 317-340.

9. Sustainable Schools for Pupils, Communities and the Environment; Delivering UK Sustainable Development Strategy; Department for Education and Skills: London, UK, 2006.

10. Sustainable Development in Action: A Curriculum Planning Guide for Schools; Qualifications and Curriculum Authority for Schools: London, UK, 2009.

11. Leading Sustainable Schools: What the Research Tells Us; National College for Leadership of Schools and Children's Services: Nottingham, UK, 2007.

12. Harris, A. Leading Sustainable Schools; Specialist Schools and Academies Trust: London, UK, 2008.

13. Education for Sustainable Development in the UK in 2010; UK National Commission for UNESCO: London, UK, 2010.

14. Keating, A.; Kerr, D.; Lopes, J.; Featherstone, G.; Benton, T. Embedding Citizenship Education in Secondary Schools in England (2002-2008): Citizenship Education Longitudinal Study Seventh Annual Report (DCSF Research Report 172); Department for Children, Schools and Families: London, UK, 2009.

15. Citizenship Established? Citizenship in Schools; Office for Standards in Education, Children's Services and Skills: London, UK, 2010. 
16. Birney, A.; Reed, J. Sustainability and Renewal: Findings from the Leading Sustainable Schools Research Project; National College for Leadership of School and Children's Services: Nottingham, UK, 2009.

17. Porritt, J.; Hopkins, D.; Birney, A.; Reed, J. Every Child's Future: Leading the Way; National College for Leadership of School and Children's Services: Nottingham, UK, 2009.

18. Dyson, A.; Gallannaugh, F. School-level Actions to Promote Community Cohesion: A Scoping Map; Technical Report from EPPI-Centre, Social Science Research Unit, Institute of Education, University of London: London, UK, 2008.

19. Education for Sustainable Development: Papers in Honour of the United Nations Decade of Education for Sustainable Development (2005-2014); Chalkley, B., Haigh, M., Higgitt, D., Eds.; Routledge: London, UK, 2008.

20. Jones, P.; Selby D.; Sterling, S. Sustainability Education: Perspectives and Practice across Higher Education; Earthscan: London, UK, 2010.

21. Sustainability Literacy: Knowledge and Skills for the Future; Forum for the Future: London, UK, 2004.

22. The Handbook of Sustainability Literacy: Skills for a Changing World; Stibbe, A., Ed.; Green Books: Dartington, UK, 2009.

23. Strategic Review of Sustainable Development within Higher Education in England; Higher Education Funding Council for England: London, UK, 2008.

24. Gough. S.R.; Scott, W.A.H. Promoting Environmental Citizenship through Learning: Towards a Theory of Change. In Environmental Citizenship; Dobson, A., Bell, D., Eds.; MIT Press: Cambridge, MA, USA, 2006; pp. 263-285.

25. Sterling, S.R.; Scott, W.A.H. Cultural Shift or Accommodation? A Snapshot of Education for Sustainable Development in English Higher Education. In Education and Sustainable Development: First Steps toward Changes; Pipere, A., Ed.; Daugavpils University Publishing House: Daugavpils, Latvia, 2007.

26. Scott, W.A.H.; Sterling, S.R. 'England report' for first international meeting on implementation of education for sustainable development for higher education institutes (IMESD). In From Cosmetic Reform to Meaningful Integration: Implementing Education for Sustainable Development in Higher Education Institutes-the State of Affairs in Six European Countries; Wals, A., Ed.; Dutch Network for Sustainable Higher Education (DHO): Amsterdam, The Netherlands, 2008.

27. Meeting the Low Carbon Skills Challenge; Department for Energy and Climate Change: London, UK, 2010.

28. Wolf, A. Does Education Matter? Myths about Education and Economic Growth; Penguin: London, UK, 2002.

29. Gough. S.R. Technical and Vocational Education and Training: An Investment-based Approach; Continuum: London, UK, 2010.

30. Kemmis, S. Getting our thinking straight: Three views of education. AdVISE 1983, 37, 1-3.

31. Berlin, I. Liberty; Hardy, H., Ed.; Oxford University Press: Oxford, UK, 2002.

32. Winch, C. Education, Work and Social Capital: Towards a New Conception of Vocational Education; Routledge: London, UK, 2000. 
33. Gough, S.R.; Scott, W.A.H. Sustainable Development and Higher Education: Paradox and Possibility; Routledge: London, UK, 2007.

34. Vare, P.; Scott, W.A.H. Two Sides and an Edge; DEA: London, UK, 2008.

35. Sen, A.K. Development as Freedom; Oxford University Press: Oxford, UK, 1999.

36. Sen, A.K. Rationality and Freedom; Belknap/Harvard University Press: Cambridge, MA, USA, 2002.

(C) 2010 by the authors; licensee MDPI, Basel, Switzerland. This article is an open access article distributed under the terms and conditions of the Creative Commons Attribution license (http://creativecommons.org/licenses/by/3.0/). 